\title{
Issues of conventional model of transfer of latent heat in soil
}

\author{
Iwao Sakaguchi ${ }^{1}$, Hidetoshi Mochizuki ${ }^{2}$, Arata Katayama ${ }^{3}$, Toshihiko Momose ${ }^{4}$, and Haruyuki Fujimaki ${ }^{1}$ \\ ${ }^{1}$ Arid Land Research Center, Tottori University, 1390 Hamasaka, Tottori 680-0001, Japan \\ ${ }^{2}$ Division of Agro-Environment Research, NARO Western Region Agricultural Research Center, 6-12-1 Nishi-Fukatsu-cho, \\ Fukuyama 721-8514, Japan \\ ${ }^{3}$ Institute of Materials and Systems for Sustainability, Nagoya University, Furo-cho Chikusa-ku, Nagoya 464-8603, Japan \\ ${ }^{4}$ Faculty of Bioresources and Environmental Sciences, Ishikawa Prefectural University, 1-308 Suematsu, Nonoichi 921-8836, Japan
}

Received October 5, 2016; accepted April 27, 2017

\begin{abstract}
A b s t r a c t. Upper limit of experimental coefficient between the measured transfer of latent heat and the estimated vapour flux in the frame of the conventional model of latent heat transfer in soil was examined by analysing the measured latent heat transfer and temperature gradient in soil under steady-state temperature gradient. To exclude the temperature gradient as an uncertainty factor from the experimental coefficient, the temperature gradients of overall soil and soil pore were included into the vapour fluxes in the atmosphere. The estimated experimental coefficient did not exceed unity, which indicated that both the latent heat transfer and the vapour fluxes in the soil were smaller than those in the atmosphere. The gap that appeared between the experimental coefficient and the product of the tortuosity factor and air-filled porosity implied the existence of an unidentified parameter relevant to characteristic of the circulation of water in soil which is the main mechanism of latent heat transfer in soil. By quantifying this characteristic with simultaneous measurements of the latent heat transfer, distributions of temperature, water content and solute content in various soils under the steady-state condition, the conventional model would be modified, or an alternative model being independent of the conventional model would be developed.

K e y w o r d s: latent heat transfer, conventional model, experimental coefficient, temperature gradient, dryland
\end{abstract}

\section{INTRODUCTION}

Even after the experimental elucidation of the mechanism of transfer of latent heat in soil under steady-state temperature gradient (Sakaguchi et al., 2009), no formula or analytical method considering the elucidated mechanism of the latent heat transfer (LHT) has been developed yet. Even though the LHT has been recognised as an error in

*Corresponding author e-mail: applebite@alrc.tottori-u.ac.jp measuring the thermal conductivity of unsaturated soil with the transient-state heat probe method (Tarnawski et al., 2013) and it is minor compared to heat conduction under atmospheric pressure and low temperature, the LHT is one of the typical phenomena of heat and mass transfer in soil. Under such circumstances, the conventional model (Cary, 1979; de Vries, 1958; Jury and Letey, 1979) and semi-empirical models (Campbell et al., 1994; Tarnawski et al., 2000) of the LHT are still used to estimate the LHT or the parameters relevant to the LHT for simulation of heat and mass transfer in soil for understanding thermal behaviour in soil, in application to agricultural and engineering fields (Fujimaki et al., 2014; Smits et al., 2013).

The conventional model of LHT assumes that the LHT is equivalent to the product of the latent heat of water and the vapour flux in soil. That is, the mechanism of vapour flow is believed to be identical to that of the LHT. This assumption has been used to investigate the experimental coefficient $(C)$ that is recognised to characterise the properties of a soil, and that can be obtained as a proportion between the LHT and the product of latent heat of water and vapour flux in atmosphere. The vapour flux in soil is described as the product of $C$ and vapour flux in atmosphere. The vapour flux in the atmosphere is shown as the product of the diffusion coefficient of vapour in the atmosphere and the gradient of vapour density. The vapour density is shown as the product of saturated vapour density and relative humidity. Temperature dependence of vapour

(C) 2017 Institute of Agrophysics, Polish Academy of Sciences 
density can be regarded as that of the saturated vapour density, and the relative humidity in soil pore calculated using the water potential of soil is approximately unity except for nearly air dry condition. The diffusion coefficient of vapour in soil is equivalent to the product of $C$ and the diffusion coefficient of vapour in the atmosphere.

The change in $C$ as a function of fluids content in soil has been focused (Cary, 1979; Cass et al., 1984; Hiraiwa and Kasubuchi, 2000; Jury and Letey, 1979; Sakaguchi et al., 2004), and almost all previous studies indicated the maximum value of $C$ exceeding unity. Hiraiwa and Kasubuchi (2000) quantified $C$ from the relationship between the product of three terms (latent heat of water, vapour flux in the atmosphere, and relative humidity in soil) and the LHT estimated from the temperature dependence of soil thermal conductivity. The obtained $C$, as the slope between them, was analysed with the change in water potential and the maximum value of the $C$ exceeded unity. On the other hand, to examine the effect of concentration of soil solution on the LHT, Sakaguchi et al. (2004) extended the theoretical model of Hiraiwa and Kasubuchi (2000) and demonstrated the maximum of $C$ to be less than unity even in solute-free condition. Because these studies were conducted under the transient-state condition, the temperature gradient in soil was not identified and it was apparently cancelled in calculating the value of $C$. However, the temperature gradient as an uncertainty factor should be actually included in the $C$.

Even though Cary $(1966,1979)$ defined $C$ as unity in the atmosphere and quantified the $C$ from the measured steady-state fluxes of water and heat in soil and the measured temperature gradient using the conventional model, the $C$ excluding the temperature gradient was not shown as a function of fluid content and no maximum value of $C$ was identified. Instead, $C$ as a function of air content was calculated from thermal conductivity of saturated soil and soil properties, and the maximum of $C$ was significantly larger than unity. Also, it was mentioned that a major component of $C$ was the ratio of temperature gradient across soil pore to that of overall soil.

Sakaguchi et al. (2009) measured the LHT, the distributions of temperature and water content in soil simultaneously under the steady-state temperature gradient for several initial water contents, and the $C$ was not estimated. From those measured data, the temperature gradient as the uncertainty factor can be eliminated from the $C$, and the $C$ as a function of water content can be estimated. This would be significantly useful to describe the LHT with consideration of the mechanism of the LHT in the frame of the conventional model. The aim of this study was to examine the upper limit of $C$ excluding the temperature gradient in the frame of the conventional model of the LHT in soil by analysing the data observed from simultaneous measurements of the LHT, distributions of temperature and water content in soil under the steady-state condition for various initial water contents.

\section{MATERIALS AND METHODS}

In the conventional model, the LHT in soil is described as follows:

$$
Q_{\text {soil }}=L J_{\text {soil }}=L C J_{\text {air }}=C Q_{\text {air }},
$$

where $Q_{\text {soil }}$ is the LHT in soil $\left(\mathrm{W} \mathrm{m}^{-2}\right), L$ is the latent heat of water $\left(\mathrm{J} \mathrm{kg}^{-1}\right), J_{\text {soil }}$ is the vapour flux in soil $\left(\mathrm{kg} \mathrm{m}^{-2} \mathrm{~s}^{-1}\right)$, $C$ is the experimental coefficient, $J_{\text {air }}$ is the vapour flux in the atmosphere $\left(\mathrm{kg} \mathrm{m}^{-2} \mathrm{~s}^{-1}\right)$, and $Q_{\text {air }}$ is the LHT in the atmosphere $\left(\mathrm{W} \mathrm{m}^{-2}\right)$.

The vapour flux and diffusion coefficient of vapour in soil are shown as follows:

$$
\begin{gathered}
J_{\text {soil }}=C J_{\text {air }}=C\left(-D_{\text {air }} h_{r} \frac{d \rho^{*}}{d T} \frac{d T}{d x}\right), \\
D_{\text {soil }}=C D_{\text {air }},
\end{gathered}
$$

where $D_{\text {air }}$ is the diffusion coefficient of vapour in the atmosphere $\left(\mathrm{m}^{2} \mathrm{~s}^{-1}\right), h_{r}$ is the relative humidity in soil pore, $d \rho^{*} d T^{-1}$ is the slope of saturated density of water vapour as a function of temperature $\left(\mathrm{kg} \mathrm{m}^{-3} \mathrm{~K}^{-1}\right), T$ is temperature $(\mathrm{K})$, $d T d x^{-1}$ is the temperature gradient $\left(\mathrm{K} \mathrm{m}^{-1}\right)$, and $D_{\text {soil }}$ is the diffusion coefficient of vapour in soil $\left(\mathrm{m}^{2} \mathrm{~s}^{-1}\right)$.

From the measured heat flux in unsaturated Ando soil (Haplic Andosols, sampled at surface layer in Shinjyo-city, Yamagata-prefecture, Japan) under temperature of $313 \mathrm{~K}$, pressure of 101-10 kPa, and the steady-state temperature gradient of $100 \mathrm{~K} \mathrm{~m}^{-1}$ conditions (Sakaguchi et al., 2009) and the thermal conductivity of air of $0.0272 \mathrm{~W} \mathrm{~m}^{-1} \mathrm{~K}^{-1}$ at $313 \mathrm{~K}$, the $d T d x^{-1}$ of soil pore was estimated because the heat flux under the steady-state temperature gradient was uniform across the soil sample. The calculated $d T d x^{-1}$ of soil pore as a function of water content and air pressure ranged within $1,600-6,100 \mathrm{~K} \mathrm{~m}^{-1}$. Those temperature gradients, the $d \rho^{*} d T^{-1}$ at $313 \mathrm{~K}$ of $2.56 \times 10^{-3} \mathrm{~kg} \mathrm{~m}^{-3} \mathrm{~K}^{-1}$, and the $D_{\text {air }}(313 \mathrm{~K}, 101-10 \mathrm{kPa})$ calculated from Massman (1998), were used to quantify the $J_{\text {air }}(313 \mathrm{~K}, 101-10 \mathrm{kPa})$ in Eq. (2). The estimated $J_{\text {air }}$ and the $J_{\text {soil }}$ in Ando soil (313 K, $101-10 \mathrm{kPa}$ ) of Sakaguchi et al. (2009) provided $C$ which was the slope between them and did not include the $d T d x^{-1}$.

\section{RESULTS AND DISCUSSION}

The $C$ as a function of the initial water content in the case of the $d T d x^{-1}$ of $100 \mathrm{~K} \mathrm{~m}^{-1}$ and $1,600-6,100 \mathrm{~K} \mathrm{~m}^{-1}$ ranged between 0.02-0.50 and 0.001-0.009, respectively (Fig. 1). For both cases, the upper limit of $C$ did not exceed unity. This is consistent with the result shown by Sakaguchi et al. (2004). The difference in the maximum value of the $C$ between Sakaguchi et al. (2004) and Hiraiwa and Kasubuchi (2000) was not due to soil texture but to erroneous analysis of the latter. The values of $d \rho^{*} d T^{-1}$ used in Hiraiwa and Kasubuchi (2000) were incorrect. The $C$ shown by Hiraiwa and Kasubuchi (2000) was reanalysed using the correct values of $d \rho^{*} d T^{1}$, and it also did not exceed unity (Fig. 2). 


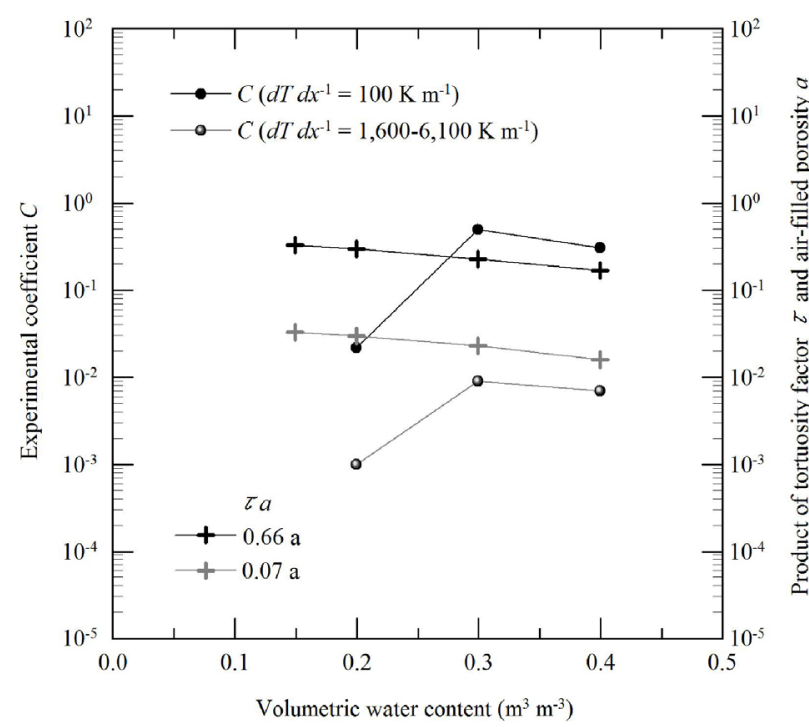

Fig. 1. Experimental coefficient, product of tortuosity factor and air-filled porosity as a function of initial water content.

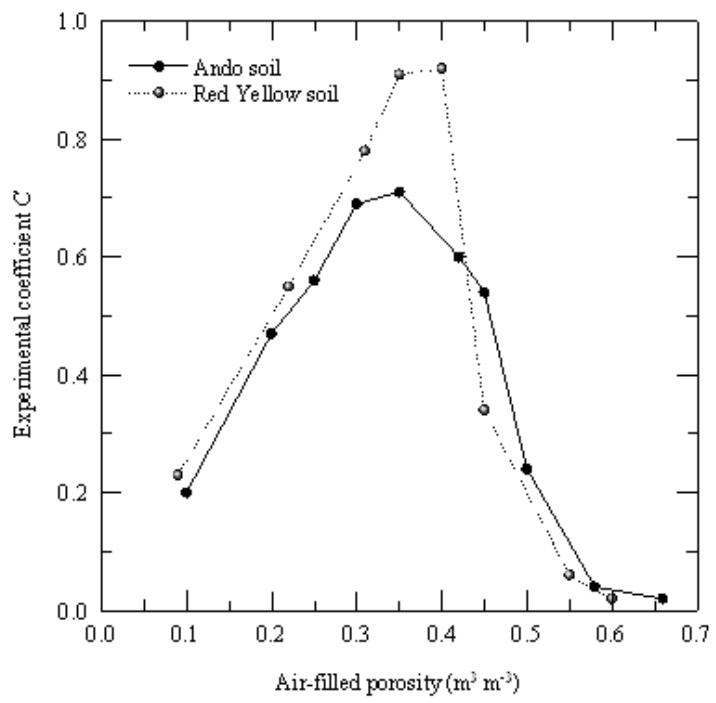

Fig. 2. Reanalysed experimental coefficients of Hiraiwa and Kasubuchi (2000).

However, because the $d T d x^{-1}$ under the transient-state condition of Hiraiwa and Kasubuchi (2000) and Sakaguchi et al. (2004) was not identified and should be actually included in the $C$, the $C$ values in those cases are still uncertain.

Even though the mass flow factor was not considered in this study, the estimated $C$ in Fig. 1 was smaller than unity. If this factor is accounted in Eq. (2), the $C$ will be further decreased because the mass flow factor is greater than unity under the reduced air pressure condition. In the following section, the $C$ in the case of the $d T d x^{-1}$ of $100 \mathrm{~K} \mathrm{~m}^{-1}$ was considered to discuss the component of the $C$, because the $C$ for this $d T d x^{-1}$ was reasonable rather than the $C$ for the $d T d x^{-1}$ of $1,600-6,100 \mathrm{~K} \mathrm{~m}^{-1}$ which was close to $10^{-4}$, the ratio of diffusion coefficient in water to that in the atmosphere, in drier condition.
The $C$ shown in Fig. 1 includes the air-filled porosity of $0.5-0.25 \mathrm{~m}^{3} \mathrm{~m}^{-3}$ (Sakaguchi et al., 2009) and the tortuosity factor of 0.66 (Penman, 1940). The product of them, shown in Fig. 1, predominated over the $C$ when the initial water content was less than $0.2 \mathrm{~m}^{3} \mathrm{~m}^{-3}$, and it was smaller than the $C$ when the initial water content was greater than $0.3 \mathrm{~m}^{3} \mathrm{~m}^{-3}$. Even if the tortuosity factor was set at 0.07 , having ten-fold larger tortuosity, this relationship was maintained. This relationship, depending on the initial water content, is consistent with the appearances of a pronounced moisture gradient and no increase in the LHT in soil when the initial water content is less than $0.2 \mathrm{~m}^{3} \mathrm{~m}^{-3}$, and with those of no moisture gradient and significant increase in the LHT in soil when the initial water content is greater than $0.3 \mathrm{~m}^{3} \mathrm{~m}^{-3}$, as observed by Sakaguchi et al. (2009). Because the mechanism of the LHT in soil is the transfer of latent heat with the circulation of water (Gurr et al., 1952; Hadley and Eisenstadt, 1955) which consists of vapour flow towards the cooler side and counter-flow of liquid towards the hotter side in soil (Sakaguchi et al., 2009), the discrepancy that appeared between the product and the $C$ (Fig. 1) should be relevant to an unidentified characteristic of the circulation of water in soil. This characteristic should be regarded as an activation or efficiency of the circulation, and would be quantified by using simultaneous measurements of the LHT, distributions of temperature, water and solute contents under the steady-state temperature gradient for various soils. Modified conventional model of the LHT based on the mechanism of the LHT, or an alternative model of the LHT being independent of the conventional model, will be required to advance experimental and theoretical analyses of the LHT in soil.

\section{CONCLUSIONS}

1. The experimental coefficient between the latent heat transfer in soil and the product of latent heat of water and vapour flux in the atmosphere, or the experimental coefficient between the vapour flux in soil and that in the atmosphere in the frame of the conventional model of the latent heat transfer in soil was quantified with excluding the temperature gradient from the experimental coefficient under the steady-state condition.

2. The upper limit of the experimental coefficient did not exceed unity. This result indicated that both the latent heat transfer and the vapour fluxes in soil were smaller than those in the atmosphere.

3. From the mechanism of the latent heat transfer in soil, the discrepancy between the experimental coefficient and the product of the tortuosity factor and the air-filled porosity implied the existence of an unidentified parameter connected to the characteristic of the circulation of water in soil.

Conflict of interest: This study was partly funded by MRA Project, Tottori University. 


\section{REFERENCES}

Campbell G.S., Jungbauer J.D. Jr, Bidlake W.R., and Hungerford R.D., 1994. Predicting the effect of temperature on soil thermal conductivity. Soil Sci., 158, 307-313.

Cary J.W., 1966. Soil moisture transport due to thermal gradients: Practical aspects. Soil Sci. Soc. Am. Proc., 30, 428-433.

Cary J.W., 1979. Soil heat transducers and water vapor flow. Soil Sci. Soc. Am. J., 43, 835-839.

Cass A., Campbell G.S., and Jones T.L., 1984. Enhancement of thermal water vapor diffusion in soil. Soil Sci. Soc. Am. J., 48, 25-32.

de Vries D.A., 1958. Simultaneous transfer of heat and moisture in porous media. Trans. Amer. Geophys. Union, 39, 909-916.

Fujimaki H., Tokumoto I., Saito T., Inoue M., Shibata M., Okazaki M., Nagaz K., and El-Mokh F., 2014. Determination of irrigation depths using a numerical model and quantitative weather forecasts and comparison with an experiment. Adv. Agric. Syst. Model., 5, 209-236.

Gurr C.G., Marshall T.J., and Hutton J.T., 1952. Movement of water in soil due to a temperature gradient. Soil Sci., 74, 335-345.

Hadley W.A. and Eisenstadt R., 1955. Thermally actuated moisture migration in granular media. Trans. Amer. Geophys. Union, 36, 615-623.
Hiraiwa Y. and Kasubuchi T., 2000. Temperature dependence of thermal conductivity of soil over a wide range of temperature $\left(5-75^{\circ} \mathrm{C}\right)$. Eur. J. Soil Sci., 51, 211-218.

Jury W.A. and Letey J.Jr., 1979. Water vapor movement in soil: Reconciliation of theory and experiment. Soil Sci. Am. J., 43, 823-827.

Massman W.J., 1998. A review of the molecular diffusivities of $\mathrm{H}_{2} \mathrm{O}, \mathrm{CO}_{2}, \mathrm{CH}_{4}, \mathrm{CO}, \mathrm{O}_{3}, \mathrm{SO}_{2}, \mathrm{NH}_{3}, \mathrm{~N}_{2} \mathrm{O}, \mathrm{NO}$, and $\mathrm{NO}_{2}$ in air, $\mathrm{O}_{2}$ and $\mathrm{N}_{2}$ near STP. Atmos. Environ., 32, 1111-1127.

Penman H.L., 1940. Gas and vapor movements in the soil. I - The diffusion of vapors through porous solids. J. Agric. Sci., 30, 437-462.

Sakaguchi I., Mochizuki H., Inoue M., and Inanaga S., 2004. Latent heat transfer in a salt-affected nonswelling clay (in Japanese). J. Jpn. Soc. Soil Phys., 98, 3-10.

Sakaguchi I., Momose T., Mochizuki H., and Kasubuchi T., 2009. Heat pipe phenomenon in soil under reduced air pressure. Eur. J. Soil Sci., 60, 110-115.

Smits K.M., Sakaki T., Howington S.E., Peters J.F., and Illangasekare T.H., 2013. Temperature dependence of thermal properties of sands across a wide range of temperature (30$70^{\circ} \mathrm{C}$ ). Vadose Zone J., doi:10.2136/vzj2012.0033.

Tarnawski V.R., Leong W.H., and Bristow K.L., 2000. Developing a temperature-dependent Kersten function for soil thermal conductivity. Int. J. Energy Res., 24, 1335-1350.

Tarnawski V.R., McCombie M.L., Momose T., Sakaguchi I., and Leong W.H., 2013. Thermal conductivity of standard sands. Part III. Full range of saturation. Int. J. Thermophys., 34, 1130-1147. 